\title{
Naturezas monumentalizadas, cotidianos politizados: a construção discursiva do lugar no caso do Quilombo Sacopã
}

\author{
Luz Stella Rodríguez Cáceres \\ Doutora em Geografia (Universidade Federal do Rio de Janeiro) \\ Pós-doutoranda na Universidade Federal do Rio de Janeiro \\ Rio de Janeiro, Brasil \\ lunsella@gmail.com
}

\begin{abstract}
Resumo A disputa decorrente da presença do Quilombo Sacopã numa área instituída como Parque Municipal José Guilherme Merquior (PMJGM) na cidade do Rio de Janeiro, em 2001, é analisada a partir da tensão existente entre monumentalidade e cotidiano. Como parte dos discursos patrimoniais, essas categorias descobrem as lógicas de apropriação e construção do lugar mediante narrativas e relatos que se desdobram nas ações de preservação ambiental e da memória cultural. O Quilombo Sacopã está conformado pelos membros da família Pinto, que se organizaram para defender o direito à moradia e a titularidade da terra que habitam desde 1920; porém, esse reclamo confronta-se com os interesses de alguns residentes de condomínios do bairro, representados pela associação de moradores, que defende interesses ambientalistas. $\mathrm{O}$ conflito exposto atenta contra a compreensão do lugar como algo pronto, estático e perfeitamente delimitado e evidencia que, como construção social, o lugar se apresenta internamente heterogêneo, constituído pela acumulação de diversas camadas de significados, suas dinâmicas e configurações são dialéticas, de relativas permanências e mudanças nos processos socioespaciais.
\end{abstract}

Palavras-chave: lugar, quilombo urbano, patrimônio cultural e natural, monumentalidade, cotidiano.

\section{O lugar e sua construção discursiva}

$\mathrm{E}$ sta análise procura abordar o conflito do Quilombo Sacopã, localizado no bairro da Lagoa, no Rio de Janeiro, a partir das configurações discursivas que constroem o espaço, considerando o valor de sintaxe espacial contido pelas estruturas narrativas (De Certeau, 2009). Mais que o suplemento de enunciações, os relatos têm o poder de produzir geografias, fundar espaços e organizar delimitações e ações.

A agência dessas narrativas se descobre com a criação, em 2001, do Parque Municipal José Guilherme Merquior (PMJGM) e na designação, em agosto de 2012, da Área de Especial Interesse Cultural (AEIC) Quilombo Sacopã, as quais se emolduram na noção de patrimônio, ${ }^{1}$ cujos alicerces se sustentam nas ideias de conservação, preservação, risco de desaparecimento e originalidade, presentes em ambos os discursos, que propõem definir, segundo seus vieses, a mesma área geográfica. Os relatos que sus-

1. O transfundo patrimonial utilizado aqui supera a noção meramente jurídica e oficial dos bens tombados e se concentra, sobretudo, nas ressonâncias advindas desses processos (Gonçalves, 2005). 
tentam essas figuras de conservação efetuam um trabalho incessante de transformação dos espaços e lugares e organizam repertórios de relações, que, como se pretende mostrar aqui, partem da instauração de uma ordem imóvel e naturalizante para uma cadeia acelerada de ações e operações definidoras dos lugares.

De outro lado, essas duas denominações oficiais se sustentam na tensão existente entre monumentalidade e cotidiano, como categorias de pensamento e classificação de lugares e patrimônios. Enquanto a criação do PMJGM fundamenta-se num processo de monumentalização da natureza e da paisagem carioca, a mais nova criação da AEIC Quilombo Sacopã dirige-se para o reconhecimento do cotidiano de uma família negra, valorizando as rodas de samba e feijoadas realizadas pela família há mais de quatro décadas, como práticas culturais que deram a esse lugar, situado no bairro da Lagoa e considerado área nobre da cidade, um caráter culturalmente diferenciado (Rodríguez, 2012).

A análise sobre o lugar do Quilombo Sacopã e do PMJGM desdobra-se de uma reflexão mais ampla dos patrimônios como gêneros discursivos que expressam visões de mundo (Gonçalves, 2002; Piazzini, 2008) e como uma estratégia de compreensão dos discursos em jogo na construção dos lugares, tendo em conta a ligação que une os discursos narrativos com os eventos espaço-temporais (Harvey, 1996; De Certeau, 2009).

A relação entre os princípios "monumentalidade" e "cotidiano" constitui-se, segundo Gonçalves (2002), ponto de partida para compreender as elaborações retóricas por trás dos patrimônios, mas também pode ser útil na compreensão dos patrimônios naturais, tidos como monumentos. O autor afirma que essa relação, que diz respeito a duas distintas modalidades de narrativas, está baseada no esforço analítico de Mikhail Bakhtin para compreender, por meio dos cronotopos, o gênero do romance em oposição ao gênero da épica. Essas categorias para a análise discursiva também servem para iluminar as duas modalidades com as quais se tem concebido patrimônio: uma ligada à materialidade, mediante a designação de "bens patrimoniais", e outra ligada à imaterialidade, por meio dos chamados "bens "culturais" (Gonçalves, 2002).

O registro "monumental" do patrimônio estaria vinculado a uma valorização do passado como fonte de autenticidade, noção que conduziria sua concepção como tentativa de reconstituir o elo com uma tradição perdida, condensado, sobretudo, a partir de monumentos capazes de darem continuidade ao passado. Já o registro "cotidiano" aparece propriamente dito nas designações dos chamados bens imateriais ou intangíveis, os quais enfatizam uma valorização da experiência, mais que da tradição (Gonçalves, 2002).

$\mathrm{Na}$ épica, o mundo representado remete ao passado absoluto, sagrado e congelado, ante o qual se tem uma atitude reverente. Há no gênero uma preocupação com a consistência e com o estabelecimento de relações de causa e efeito, a fim de constituir coerência e gerar sentido (Gonçalves, 2002). Como tradicionalmente o passado, representado em monumentos de cal e pedra, tem recorrido a "termos épicos", proponho mostrar como a natureza vem sendo tratada nesse mesmo patamar pelas agendas ambientalistas, conduzindo a sua monumentalização e tornando-a objeto de reverência.

O conteúdo da épica não se baseia na experiência pessoal e cotidiana, pois está separado do presente no tempo e no espaço do lugar onde estão situados o narrador e seu interlocutor, ou os fazedores do cotidiano. Ao estar afastada do cotidiano, a dimensão monumental, como a que assume um objeto ou lugar, promove a tendência de policiar os comportamentos que possam chegar a corromper ou deixar eivada a monumentalidade. Em outras palavras, o monumental deve ser defendido de qualquer tentativa de relativização que possa partir de indivíduos e grupos sociais situados na realidade cotidiana (Gonçalves, 2002, p. 120).

Em outro sentido, o romance seria o gênero que se alinha melhor ao discurso do cotidiano, cujo alicerce é um presente que não se ajusta à "ilusão retórica" do relato coerente, pois o real é descontínuo, formado por elementos justapostos sem propósito aparente, todos eles únicos e difíceis de apreensão, surgindo imprevisível e aleatoriamente. Para De Certeau (2009, p. 141), o cotidiano é uma pluralidade temporal atravessada por várias perspectivas, que podem ser tão díspares quanto complementares.

Assim, a narrativa do cotidiano possui um caráter eminentemente dialógico, do qual brota o confronto permanente entre diferentes pontos de vista e subjetividades. Nesse tipo de narrativa, a relação com o passado é mediada pela experiência pessoal do dia a dia. Em virtude de sua sinuosidade ante as circunstâncias do momento e às transformações dadas pelo tempo, o romance é um relato aberto, maleável diante das incertezas oferecidas pelo devir (Gonçalves, 2002).

A reflexão sobre monumentalidade e cotidiano resulta útil para guiar a análise sobre cada uma das designações que aparecem no caso Sacopã, pois, pelos seus conteúdos e propósitos, o PMJGM e a AEIC bem poderiam estar representados, respectivamente, por essas categorias. Se por um lado a tensão entre monumentalidade e cotidiano fala-nos da multiplicidade, da dinamicidade e da multivocalidade do lugar, tornando relevante a procura pelos múltiplos sentidos deste (Rodman, 2003), por outro é necessário entender que essa relação não aparece de forma excludente ou tipológica, pois ambas as dimensões comparecem de forma dialética. Vejamos agora o contexto que alimenta as duas designações. 


\section{Do cotidiano censurado de uma família negra}

O Quilombo Sacopã é conformado pelos membros da família Pinto, que moram na Ladeira Sacopã, numa encosta do Morro dos Cabritos, desde os anos 1920. A área, localizada no bairro da Lagoa, manteve-se relativamente bem preservada em termos "ambientais", por causa dos usos e práticas do espaço da família, como também por seu "difícil" acesso para outro tipo de empreendimento. O lugar, emoldurado por remanescentes da Mata Atlântica, possui grande beleza cênica, e a vista para o Corcovado e a Lagoa Rodrigo Freitas faz do conjunto uma paisagem que adquiriu um traço de exclusividade e distinção, tornando-se objeto de disputa simbólica (Rodríguez, 2012).

Desde a remoção das favelas do entorno da Lagoa, na década de 1970 - à qual a família resistiu -, o lugar tem sido cobiçado pelos especuladores imobiliários, insistentemente. Estes transformaram a área num luxuoso bairro, mediante um modelo de acelerada urbanização, cuja verticalidade deu origem à singular paisagem de poder (Zukin, 2000) que hoje caracteriza a Lagoa, um dos bairros com o metro quadrado mais caro do Rio de Janeiro. Talvez o maior símbolo do refinamento da área seja o atual Parque Marcos Tamoyo, montado sobre o que outro dia fora a favela da Catacumba. O parque é resultado de uma sólida obra de ajardinamento e paisagismo que criou no local um espaço suntuoso e agradável, formado por alamedas, praças e jardins, com muitas árvores que emolduram uma exposição ao ar livre de esculturas de artistas famosos.

A paisagem hoje disputada é diferente da que acharam Manoel e sua esposa dona Eva Manuela, o casal que deu origem à família Pinto. Proveniente de Friburgo, o casal achou nas imediações da Lagoa uma área pouco habitada e desenvolvida, mas em véspera de mudanças. No ato de habitar aquele espaço e torná-lo seu lugar, Eva, Manoel, seus filhos e netos participaram ativamente dos processos de construção e transformação do bairro.

A saga da família Pinto na ladeira Sacopã ilustra o entrecruzamento de práticas locais particulares com o poder econômico e político na construção social do lugar. É impossível examinar um sem o outro. Segundo Mosquito, um dos filhos do casal, antes de ir para o Rio de Janeiro sua família peregrinou de fazenda em fazenda. Manoel, seu pai, sabia de agricultura, mas uma vez na cidade ele incursionou em vários trabalhos, trabalhou, por exemplo, na abertura das ruas da Lagoa, Sacopã entre elas, e mais adiante em Humaitá.

Manoel Pinto foi contratado como faxineiro e jardineiro de Astréia Darke, que além de ser dona da indústria de alimentos Bhering, fabricante de chocolate e do Café Globo, era também proprietária de toda extensão de terras que formam o bairro da Lagoa, desde o atual Parque da Catacumba até a atual ladeira Sacopã, área onde havia até 1912 uma plantação de café. Influenciados pelo auge da expansão urbana no fim da década de 1930, quando o prefeito Carlos Sampaio mandou realizar importantes obras de saneamento, o aterro e a canalização de rios na Lagoa Rodrigo de Freitas. Astréia Darke de Matos e Adauto Durão criaram a Incorporadora Darke para fazer ruas no bairro.

Com o passar do tempo, Manoel chegou a tornar-se empregado de confiança de Astréia e passou também a tomar conta da sua casa. Antes da sua morte, Astréia teria cedido um pedaço de terra à crescente família de Manoel; ${ }^{2}$ porém, essa doação não foi reconhecida pela família e, por isso, foi incorporada ao patrimônio da Imobiliária Darke. Assim, o loteamento dos terrenos na ladeira Sacopã foi registrado em nome da imobiliária, e uma parte deles cedida ao município para arruamento e uma área de reserva. ${ }^{3}$ Alheios a essas transações comerciais e cadastrais, Manoel e sua família continuaram a morar no local do mesmo jeito. Em um depoimento ao jornalista Carlos Marques (1986), da revista Isto é, o senhor Pinto, que nesse momento tinha 90 anos, narrou: "Construí meu barraco aqui e trabalhei nas terras dela [de Astréia] durante quase trinta anos. Aqui nasceram meus filhos, netos e bisnetos. Dessa terra receberam seus primeiros alimentos, era minha mulher que os plantava".

Eva Manoela trabalhava como copeira, lavadeira e doméstica na casa do então governador Chagas Freitas, que era morador da rua, numa residência que hoje deu lugar a um edifício. Além disso, era curandeira e parteira, e atendeu o nascimento de muitas crianças das favelas da Lagoa, sendo por isso chamada de "vó de umbigo". Outros membros da família Pinto já serviram de diferentes formas às famílias que habitam nos edifícios de apartamentos e estabeleceram com eles relações laborais. Uns já foram jardineiros, caseiros, pedreiros, motoristas, outros sapateiros, taxistas e empregadas domésticas. Os mais velhos trabalharam nas obras de abertura das ruas e avenidas que hoje caracterizam o bairro, e ao fundar uma pequena pen-

2. A família Bhering, que conformou mais tarde a empresa imobiliária Darke S.A. e propôs o loteamento da área, desconhece essa doação e afirma que aquela relação era apenas um acordo temporário, do qual não existem provas escritas. O não reconhecimento da doação é a fonte de conflito e desencontro entre a família quilombola e os demais moradores da Fonte da Saudade.

3. Essa área destinada a reserva florestal deu-se mais em função da difícil topografia do lugar, não suscetível de construção. Não existia na época o conceito de parque público como se entende hoje em dia, tampouco existia uma cultura jurídica de proteção ao meio ambiente. Por muito tempo essa área não foi identificada, individualizada ou reconhecida pelo município. 
são, forneceram alimentação aos pedreiros, muitos deles nordestinos, que colocaram em pé os altos edifícios da ladeira Sacopã e outras ladeiras vizinhas à Rua Fonte da Saudade. Anos mais tarde, a experiência da família no atendimento ao público se aliou ao talento artístico de Luís Sacopã e sua irmã, Tia Neném, filhos de Manoel e Eva, para promover ali feijoadas e rodas de samba, que atraíam muito público, tornando bem conhecido o lugar.

Esse lugar de vivências e disputas é parte constituinte da identidade da família, e amiúde o grupo familiar também é identificado como a família Sacopã, Sacopã como o logradouro, como a ladeira, como o próprio Luís. Atual liderança da luta familiar e quilombola, ele tem esse apelido desde criança, quando a moçada o identificava como o Luís dessa rua, desse lugar, cuja agência transformou o caráter da luta e a eles mesmos em quilombolas. A agência do lugar é avaliada por Rodman (2003, p. 209) pelo seu papel na formação permanente da experiência das pessoas, o que também aponta, em outras palavras, para sua incidência na produção da autoconsciência, pela forma como os lugares são apreendidos e narrados pelas pessoas e os valores que lhe são adjudicados, e que por esse meio se narram e se produzem a si mesmas.

Desde há mais de 40 anos, a família luta pelo reconhecimento legal da sua posse, em meio a agudas disputas judiciais, pois são várias as ações que compõem um intricado caminho de idas e vindas ante a justiça comum. Nos anos 1970, a família Pinto impetrou uma ação de usucapião, reivindicando $18.000 \mathrm{~m}^{2}$; contudo, o primeiro julgamento só foi realizado em 2002 e a ação continua em andamento.

Em 2005 a família deu início ao processo de autorreconhecimento como comunidade remanescente de quilombo. Da Fundação Cultural Palmares, recebeu o certificado de identificação de remanescente de quilombo, de acordo com o dispositivo constitucional, o artigo 68 dos Atos das Disposições Transitórias Constitucionais (ADTC). A partir de então, o Instituto de Colonização e Reforma Agrária (Incra) entrou no processo. Como parte do relatório técnico, o Incra produziu uma primeira demarcação do território familiar, cujo polígono corresponde a $23.900 \mathrm{~m}^{2} \mathrm{~A}$ publicação do relatório produziu inúmeras contestações por parte da vizinhança, levando à realização de uma segunda demarcação por parte do Incra, que reduziu a área inicialmente reivindicada a $6.900 \mathrm{~m}^{2}$, (Rodríguez, 2012) (ver Anexos, Mapa 2).

As contestações da vizinhança não se reduziram apenas à demarcação territorial, pois também têm atacado as práticas culturais e de subsistência da família. Em diferentes épocas e sob argumentos que passam pela higiene, pelo caráter residencial da área e pela se- gurança, já foram coibidas a cultura de plantas frutíferas e alimentícias, e a criação de galinhas e porcos. A oficina de mecânica automotora também foi suspensa, e o serviço de garagem, oferecido num espaço do terreno, é ainda contestado por alguns moradores que rodeiam o espaço da família. Desde que a área habitada foi englobada pelo PMJGM em 2001, a lista de proibições cresceu, sendo proibida a construção de novas casas, assim como a reparação ou ampliação das existentes e o uso de qualquer material vegetal. À tona, com certo tipo de discurso ambiental, as atividades e a presença humana são qualificadas como incompatíveis.

Porém, a massa verde que é vista por alguns moradores e ambientalistas, com dados técnicos e estadísticos para produzir regulamentações e traçar limites, guarda para a família outra série de sentidos, afetos e emoções, constituintes primordiais de sua identidade com o lugar. Mais do que modos de sobrevivência, as práticas do espaço se relacionam com a história dos membros da família e suas práticas. A criação de espécies menores e a cultura de plantas alimentícias e flores, por exemplo, é entendida como uma continuidade com os parentes mortos, que quando em vida se envolviam com essas rotinas. Por isto, o atual impedimento de práticas espaciais da família, promovido por autoridades e outros moradores, é, além de um bloqueio das fontes de subsistência, uma ruptura de comunicação com os ancestrais e com o lugar a partir do qual a família Pinto tem se relacionado com o universo mais amplo que é a cidade.

Diante das normativas ambientalistas sobre as quais os mapas e outras representações discursam, o mesmo espaço é vivenciado pela família a partir de sua experiência e prática cotidiana. Isto é continuamente narrado em anedotas e relatos que dão conta do enraizamento e a domesticação do espaço. Os marcadores da relação da família com a denominada Mata Atlântica falam de outro tipo de mediações com o mundo natural (ver Anexos, Mapa 2). Muitas das narrações por mim coletadas remetem às lutas entre venenosas cobras e homens "curados" que as conseguiram vencer. Por trás de cada semente plantada há um relato de conquista e, entre as pedras, trilhas e cavernas dormem os sonhos de infância de alguns membros. Outros relatos de espaço rememoram as lutas pela canalização da água, o uso de bambus e folhas de bananeira, de um esforço equiparável aos anos e aos suores para aterrar o que hoje é o centro da vida em família e a pública e social: a cozinha e o salão do pagode. Mas também essas narrações dão conta das amargas dificuldades e dos conflitos próprios da organização, diante da vizinhança e das políticas municipais que os agridem.

Até dezembro de 2011, a única atividade que tinha conseguido sobreviver aos embates da vizinhança 
era a feijoada, realizada aos segundos sábados de cada mês. Era um evento animado por uma roda de samba entre as 14 e 19 horas, e eventualmente participavam passistas de samba e foliões do bloco de carnaval "Rola Preguiçosa", do qual a família é cofundadora.

O pagode e a feijoada tornaram-se uma ferramenta poderosa da família para produzir alianças, despertar simpatias e fomentar o apoio de certa classe política, artística e intelectual da cidade. A família Sacopã ficou conhecida na zona sul, quando seus encontros passaram a reunir bambas do samba carioca numa tradicional feijoada familiar. A roda de samba ganhou fama e virou atração turística, atraindo ao lugar os mais variados frequentadores, como os renomados artistas Tim Maia, João Nogueira, Zeca Pagodinho, Beth Carvalho, Dona Ivone Lara, Zezé Motta e Arlindo Cruz, entre outros.

Esses encontros gastronômicos e musicais tampouco ficaram à margem de conflitos, pois nasceram no conflito mesmo e têm permanecido nele de maneira intermitente, tendo sido interditados várias vezes. Em mais de uma oportunidade a sua legalidade foi questionada, indo parar nas esferas judiciais; em vários outros momentos, a família conseguiu negociar e fazer algumas concessões para continuar com os eventos.

Assim, com a mesma eficácia que as rodas de samba e a feijoada foram úteis para criar alianças, também foram decisivas para gerar adversários e fortalecer a lista de argumentos contra a presença da família negra nessa área da cidade. Em julho de 2011, um desembargador, vizinho e parte no litígio, mandou acorrentar os portões do Quilombo Sacopã para impedir que uma companhia de táxi utilizasse o estacionamento do quilombo como área de apoio aos seus motoristas, dando início a uma ação judicial. A suspensão do lacre nos portões do Quilombo se deu com a condição de não retornarem mais as já citadas ações culturais no local. Em que pese o fato de a família ter recorrido da decisão do juiz, os representantes dos condomínios conseguiram, em março de 2012, uma liminar na Justiça proibindo a realização das rodas de samba e feijoadas, sob o argumento de que habitam uma área estritamente residencial, incompatível, conforme o tipo de zoneamento, com a realização de atividades comerciais.

\section{A natureza como épica}

O Parque Municipal José Guilherme Merquior foi criado pela Prefeitura do Rio de Janeiro com o Decreto Municipal n. 19.143, de novembro do ano 2000. ${ }^{5}$ Uma grande parte da sua área se sobrepõe à área habitada pela família. Além do Parque, também funcionam como figuras de conservação três Áreas de Preservação Ambiental (APA). ${ }^{6}$

A demarcação do PMJGM foi liderada pelo então vereador Alfredo Sirkis, do Partido Verde. Segundo ele, a iniciativa atendia ao pedido de uma comunidade preocupada simultaneamente com o desmatamento dos morros e os processos de favelização, que, para alguns, eram concomitantes, daí o significativo apoio cidadão. Por outro lado, a demarcação dessas áreas colocou em evidência a mobilização de influências políticas e econômicas e a recriação de alianças de classe para pressionar o poder público.

O levantamento cartográfico das figuras de proteção ambiental indica uma sobreposição dessas figuras na mesma área, uma redundância que também pode ser lida como a ênfase de um discurso preservacionista que precisa de repetição e reforço contínuo (Rodríguez, 2012): 1) a APA do Sacopã7; 2) a APA Morro dos Cabritos; e 3) a APA Morro da Saudade. A primeira APA delimitada com parâmetros urbanísticos definidos foi Sacopã, em 1986. Já as APA Morros da Saudade e Morro dos Cabritos foram criadas pela mesma Lei n. 1.912 19/92 que fundou o PJGM, mas sua delimitação ainda é provisória (ver Anexos, Mapa 3).

Para alguns dos proprietários de condomínios do bairro, e especialmente para a Associação de Moradores da Fonte da Saudade (Amofonte), a solução definitiva para a preservação dos remanescentes da Mata Atlântica que ainda cobrem alguns dos morros no entorno da área e também para conter as denominadas "ocupações irregulares" passa pela criação de Áreas de Preservação Ambiental e parques naturais devidamente delimitados e cercados. Apesar de a Lei n. 1.912/1992 não contemplar a expulsão de moradores em situação irregular, o propósito era sua contenção.

O compromisso da sociedade civil com a degradação de áreas pelos impactos humanos foi rapidamente assumido por alguns dos setores sociais da região do

\footnotetext{
5. O parque natural é uma unidade de conservação de proteção integral criada pelo município com o objetivo básico de preservar ecossistemas naturais de grande relevância ecológica e beleza (SNUC, art.11). As unidades de proteção procuram a preservação da natureza e permitem apenas o uso indireto dos seus recursos ambientais, sendo proibido o consumo, a coleta, dano ou destruição dos recursos naturais. Também não é permitida a presença de moradores nas unidades de proteção integral (SNUC, art. $2^{\circ}$, inc. $X_{1}$ ).
}

6. Área em geral extensa, com certo grau de ocupação humana, dotada de atributos abióticos, bióticos, estéticos ou culturais especialmente importantes para a qualidade de vida e o bem-estar das populações humanas. Tem como objetivos básicos proteger a diversidade biológica, disciplinar o processo de ocupação e assegurar a sustentabilidade do uso dos recursos naturais.

7. A APA de Sacopã foi criada pelo Decreto n. $6.231 / 1986$ e limita a ocupação do espaço ( $10 \%$ do lote, no caso dos terrenos acima da curva de nível de cem metros). O uso da área é restrito a residências, que não podem ter mais de 11 metros de altura (três andares). Os trechos de encosta, com declividade igual ou superior a 45 graus, são considerados de proteção à vida silvestre e sua vegetação deve ser mantida intacta. 
entorno da Lagoa Rodrigo de Freitas. Nesse processo, a Amofonte tem sido um importante ator, canalizador de uma demanda social que vê na expulsão da família quilombola um meio para a preservação da Mata Atlântica.

Contudo, o PMJGM não possui plano de manejo ou inventários de fauna e flora. Segundo um funcionário da Gerência de Unidades de Conservação da Secretaria Municipal de Meio Ambiente, em relação a outros parques, o PMJGM é uma área pequena demais e de pouco significado ambiental. Porém, sua preservação é uma bandeira de luta local, que tem provocado a mobilização de vários residentes, que se sentem chamados a proteger o patrimônio ambiental. ${ }^{8}$ Um exemplo é o depoimento do biólogo Celso Sanchez, vizinho da área, que se mostrou constrangido com a transformação de uma área pública em privada, pelos riscos que isso implicaria para o meio ambiente. Referindo-se à permanência da família Pinto no lugar afirmou:

Não sabemos como essas pessoas, no âmbito privado, vão conseguir dar conta da preservação dessa área, que é muito grande. Se o próprio poder público tem dificuldade para fiscalizar, imagina a responsabilidade que têm pessoas particulares para fazerem essa fiscalização. É um problema grave. (RJTV Globo, 2008)

Como se sabe, a categoria de risco opera por trás de muitas declaratórias patrimoniais e é parte de uma preocupação ligada à incerteza sobre o futuro e a consequente necessidade de reagir, desde o presente, para combater seus possíveis danos (Beck, 2002, p. 5). No caso analisado, a natureza apresenta-se suscetível ao desaparecimento, a ser contaminada e corrompida.

Os vizinhos, preocupados com a área, têm se organizado para pedir reiteradamente que a área seja cercada, para conter as ações dos "criminosos", como amiúde são classificados os membros da família. Em depoimento, a advogada da Amofonte, Regina Carquejo, ratificou que "foi para impedir a destruição daquela mata, que é nosso patrimônio ambiental, que entramos com uma ação sob a alegação de crime ambiental" (Milhorance, 2010).

De acordo com a legislação, a criação das APA objetiva: a preservação da cobertura vegetal existente; o desenvolvimento do estudo e pesquisa acerca da fauna e da flora; o desenvolvimento da educação ambien- tal; a viabilização da criação dos parques municipais e o desenvolvimento do lazer. A criação delas contempla também, e de modo principal, a preservação de animais e espécies vegetais ameaçados de extinção e a preservação e recuperação do relevo, considerados como patrimônio ambiental da cidade.

A natureza das APA não é incompatível com a residência ou moradia, já a figura do parque a impede totalmente. A área do parque se sobrepõe, em grande percentagem, ao território sobre o qual a família demanda titulação; a sua criação é lida pela família como mais uma das estratégias, agora vestida de verde, para legitimar a sua expulsão do lugar.

A partir do início do processo administrativo no Incra, para seu reconhecimento como comunidade quilombola, a família não pôde mais ser expulsa, mas não é poupada do impedimento de realizar modificações no entorno. Suas atividades ainda são vistas como um atentado ao mundo natural, agora sacralizado, e sob o argumento de evitar qualquer ação que coloque em risco a área do Parque, são permanentemente vigiadas e censuradas. É aqui, quando os enfoques preservacionistas exercem policiamentos sobre o cotidiano das populações, que residem em áreas de conservação, que se reconhece um traço da monumentalização da natureza. Sob essa ótica, a presença da família é vista como uma ameaça ao reino da natureza e por isso é combatida, mesmo que o dito "monumento natural" certamente tenha sido "edificado" pelo habitar e pelas práticas da família no lugar.

A monumentalização da natureza tem como fontes a emergência de um discurso ambientalista ${ }^{9} \mathrm{em}$ primeiro lugar, e seu entrelaçamento com os patrimônios culturais, em segundo lugar. Na primeira instância, lida-se com a dupla transformação - social e global - da noção de natureza, que transita, nas décadas de 1970 e 1980, para o conceito de meio ambiente e, nos anos 1990, para a ideia de biodiversidade e conservação. Esta última, com um forte apelo à recuperação de uma natureza prístina e intocada, que Diegues (1996) localizou no plano mítico, ${ }^{10}$ ao ser qualificada de absoluta, original, anterior à própria humanidade e externa à cultura e ao cotidiano humano.

A busca por um mundo prístino e puro tornou a originalidade natural um importante atributo de valor, porque o nível atingido hoje pela antropomorfização do globo leva a que os lugares com quadros naturais "intocados" apareçam hoje como residuais e raros

8. Certamente o temor dos moradores de condomínios vai além da presença do quilombo, estendendo-se ao crescimento da favela no Morro dos Cabritos e na Ladeira dos Tabajaras.

9. A emergência de uma "consciência preservacionista" na esfera ambiental consolidou-se na década de 1980, mas essa mobilização não partiu do Estado, como ocorreu com o patrimônio histórico, pelo contrário, se irradiou por meio da comunidade científica e de uma mobilização social global para reivindicar melhor "qualidade de vida" no planeta (Fonseca, 1996; Ulloa, 2003).

10. Para explicar as ideias que antecedem à criação de parques naturais e reservas ambientais, Diegues (1996) retoma o conceito antropológico de mito, para a compreensão das formas como foi consolidando-se no pensamento ocidental o mito, essencialmente moderno, da natureza intocada, sustentado no imaginário da existência de uma natureza prístina e originaria não "corrompida" pela ação humana. 
em termos absolutos (Moraes, 2004; Harvey, 1996). O mito da natureza intocada emerge do olhar "biocêntrico" e tem sua origem nas correntes do século XIX, e hoje se vê reforçado pelo fervor religioso que lhe outorgam grupos sociais e instituições que se autoatribuem o papel de guardiões da natureza e propõem o afastamento dos grupos humanos e suas atividades como forma de protegê-la (Diegues, 1996).

O segundo aspecto da natureza como monumento liga-se à categoria do patrimônio, atrelada, por um lado, à noção do patrimônio como reserva ou legado para o futuro, considerando-se sua etimologia (bens pertencentes ao pater referente à herança paterna), e como um desdobramento do patrimônio cultural, vinculado a processos identitários e de memória.

Segundo Moraes (2004), o patrimônio natural define-se pela diversificação natural dos lugares, que expressa desigualmente fenômenos e processos naturais nos espaços. Essa natureza requalificada pela mediação da sociedade (conhecimento, inventário, exploração, técnica, atribuições de valores e potenciais de reserva) circunscreve como riqueza natural o conjunto de recursos naturais de um dado meio, depositada num determinado espaço.

Essa ideia é reforçada com o "enfoque patrimonial" para a gestão dos recursos naturais (Ollagnon, 1997, p. 176), definido por seus promotores como a constituição de uma metalinguagem para tornar natureza e recursos um "bem comum" da sociedade. ${ }^{11}$ Essa ideia move particularmente a Amofonte, que, uma vez notificada da primeira demarcação do território do Quilombo Sacopã, manifestou:

A AMOFONTE repudia a atitude do INCRA, que vem, através de um processo administrativo, tentando se sobrepor a uma decisão judicial. A Família Pinto perdeu por $3 \mathrm{x} 0$ uma ação de usucapião onde solicitava dezoito mil metros quadrados de terra em nosso Parque. Mesmo assim, o INCRA notificou 22 condomínios em nossa área de abrangência, dando ciência que delimitou mais de vinte e quatro mil metros quadrados, incluindo todo o Parque Municipal José Guilherme Merquior, em favor da Família Pinto. A decisão causou perplexidade não só às 220 famílias que residem nos imóveis notificados e tem os mesmos devida- mente regularizados e inscritos no RGI, assim como a todos os vizinhos de nossa área de abrangência, pois é uma tentativa de ferir o DIREITO À PROPRIEDADE PRIVADA e decisão judicial unânime do Tribunal. A área do Parque Municipal José Guilherme Merquior constitui propriedade municipal, qualificado como bem público de uso comum do povo, não sendo, portanto, passível de apropriação por quem quer que seja. ${ }^{12}$ [caixa alta do original]

Foi com a Conferência da ONU sobre Meio Ambiente e Desenvolvimento, realizada no Rio de Janeiro em 1992, que a preocupação com o patrimônio para as gerações futuras veio a consolidar-se (Moraes, 2004). A natureza, tratada como "bem comum", apela para um referente de indivisibilidade e à universalidade de um titular anônimo e genérico: a humanidade, que asseguraria seu cuidado e sua transmissibilidade para as próximas gerações. A concepção de "legado" para a posteridade surge em nome de um interesse público que fomentaria a consciência do uso comum do meio e a responsabilidade coletiva de seu cuidado.

Nos discursos sobre natureza, quanto mais palpável e visível é o objeto natural, maior é o manifesto de realidade e a operacionalidade social que lhe outorga o discurso sobre ele produzido. É como se o tamanho material do objeto reafirmasse a própria coerência do discurso científico ou popular, ilustrando algum tipo de verdade. No caso da natureza, o discurso multiplica a tendência generalizada de associar a monumentalidade à grandeza e à imensidão, como adjetivos. ${ }^{13}$

Vista como atemporal e transcendente, não é fácil fugir do caráter monumental que se imputa à natureza: ela é definida na sua grandeza como imponente, eterna e permanente, original e fonte de autenticidade. ${ }^{14}$ Como todo objeto monumentalizado, possui um efetivo poder sedutor. Contudo, antes de sua escala e tamanho, a monumentalidade está vinculada à lembrança coletiva, ao memorável e comemorável. Porém, esse caráter foi alterado no curso do século XV, quando o sentido estético e a beleza, associados ao poder e à grandiosidade, começaram a ser a expressão maior do monumento (Choay, 2001).

O patrimônio natural é considerado como uma evolução do patrimônio cultural porque este coadu-

11. "O enfoque patrimonial torna-se necessário para o esforço de gestão de certos bens, a partir do momento em que sua degradação ou sua destruição alteram a autonomia e a identidade de um titular [...] A manutenção da qualidade de um objeto da natureza resulta, assim de um engajamento humano efetivo, que permite manter as propriedades globais do meio, na ausência do qual as atividades humanas usuais tenderiam a degradá-las" (Ollagnon, 1997, p. 194).

\section{Disponível em: https://groups.google.com/group/amajb/msg/bf4e03edb89f869a?hl=pt\&pli=1}

13. Nos estudos sobre monumentos, Corrêa (2005, p. 35) explica que a escala deles não deve ser depreciável. Entendida na sua dimensão absoluta, a escala abrange área, volume e altura, e na sua dimensão relacional existe sempre uma tendência à comparação com outros monumentos. Nesse sentido, o tamanho tem uma conotação de poder e supremacia.

14. Como nenhum outro objeto, a natureza possui uma enorme e complexa carga simbólica. Representada de muitas formas, ela pode ser feminina, estética, harmoniosa, definidora, original, misteriosa, primordial, selvagem oposta à sociedade e à cultura. Objeto a ser dominado, domesticado, explorado, reservado, mas também a ser admirado, protegido e valorado na sua escassez (Lovejoy, 1948). 
na as noções de bens culturais e naturais, concatenadas mediante as articulações entre natureza e cultura. Patrimonializar bens da natureza é gestar uma outra mediação entre cultura e natureza.

Se bem a valorização da natureza é colocada como o fruto de uma conquista social que mobilizou uma nova agenda mundial, é preciso ressaltar que não existe nenhuma ideia genérica ou neutra de natureza. ${ }^{15}$ Será sempre necessário determinar de que natureza se trata e quais os sujeitos que a reivindicam, pois "o ambiental" é tão impreciso quanto insuficiente para compreender a visão de mundo contida nas linhas discursivas (Harvey, 1996). Em muitos casos, a defesa da natureza aparece dotada do sentido para afiançar signos da identidade cultural, nacional, étnica de classe e ecológica ao mesmo tempo. ${ }^{16}$ Deste modo, a natureza referenda representações de memórias coletivas e aporta elementos subjetivos, fundadores das identidades individuais e coletivas. $\mathrm{O}$ ato de tornar a natureza um patrimônio é uma estratégia política para narrar memória e identidade.

Diante do enfoque conservacionista de natureza, ancorado na incompatibilidade da existência humana e da conservação da natureza, os movimentos sociais e as ciências sociais desenvolveram uma base crítica para contestar as restrições oficiais à presença humana e suas atividades cotidianas nas áreas de proteção ambiental.

Hoje várias unidades de mobilização social desprendem da natureza autodefinições coletivas, politizando assim as nomeações da vida cotidiana, anunciando certo modo de viver e valorizando práticas rotineiras de habitar. Desse modo, atinge-se uma politização da natureza, tornando-a lugar público de reconhecimento, representação e pertencimento (Almeida, 2008).

Contudo, o que pretendo ressaltar é que a natureza é um lugar para o reconhecimento, a representação e o pertencimento, mas não só de populações tradicionais e residentes. $\mathrm{O}$ caso analisado indica como a natureza pode ser discursada como estratégia para segregar e excluir, mas ela também é fonte de identidade para as elites urbanas que, rodeadas pela sua presença, constroem um status de distinção social. As distintas ações civis contra a família vêm confirmar também como as "amenidades naturais" viraram um privilégio das classes favorecidas e que o dito "natural" contém um status de exclusividade e luxo, do qual têm de ser excluídos os que por ele não podem pagar. Basta dar uma olhada nos anúncios classificados de apartamentos nessa região. "Vista para o verde", "barulho de mata" e "perto da natureza" aparecem como atributos principais de valorização.

\section{Monumentalidade e cotidiano}

Colocado sob a perspectiva analítica que venho desenvolvendo, o caso Quilombo Sacopã vem nos falar das relações existentes entre monumentalidade e cotidiano. Longe de constituírem uma distinção ontológica, tais termos supõem diversas relações de sentido, dadas pelo caráter dialógico entre as narrativas, a permeabilidade dos discursos e a mútua incorporação dos seus elementos.

Brandão (2006) considera que é do cotidiano que a monumentalidade retira seus significados, e que é sobre as urgências e contingências dele que o monumento se ergue. Seria para o caráter amorfo ou indistinto do cotidiano que se dirigem os discursos plenos de coerência e sentido do monumento.

Nessa perspectiva, a família Pinto habita mais que um lugar, uma monumentalidade, e é ali que eles construíram um monumento do cotidiano que sacraliza, antes de tudo, o presente vivido e real, que surge do modo particular de habitar o mundo e da experiência ativa tirada de estar nele, por meio do lugar. As especificidades desse cotidiano transcendem as representações possíveis desde fora e tornam-se apreensíveis mediante tecidos narrativos e outras estratégias discursivas.

E se bem há um cotidiano "proibido", há de se reconhecer que as práticas rotineiras e as "artes de fazer" o espaço dessa família (De Certeau, 2009) foram elementos na construção dessa natureza hoje reverenciada. Outra seria a sorte daquela área em mãos dos empreendedores imobiliários, dos quais a família recebeu inúmeras ofertas de compra, com a esperança de explorar a área. Neste sentido, podemos pensar que o caráter monumental afirma, mais que o majestoso ou o excepcional, a síntese de um cotidiano que por essa via torna-se público (Brandão, 2006).

$\mathrm{Na}$ continuação, quero analisar a forma como se apresentam monumentalidade e cotidiano em dois fragmentos de discursos, emanados a partir de um incêndio no PMJGM. Em junho de 2010 houve um devastador incêndio na área florestal de Sacopã. A dificuldade do Corpo de Bombeiros para apagar o fogo foi enorme, pois, como demoraram a chegar à área atingida, o fogo alcançou proporções maiores. Dias após o incêndio, a Amofonte convocou seus associados

15. Quando o assunto é a natureza, não tratamos apenas de um objeto biológico e geográfico, e sim de um produto discursivo e narrativo oficial ou não, baseado nos conhecimentos e consensos produzidos socialmente, os quais fundamentam outros discursos políticos e econômicos que justificam ações materiais e imateriais sobre a natureza. A ideia de "natureza" é uma elaboração social, construída historicamente, cujo valor está em permanente mudança e transita necessariamente pelo mundo das ideologias.

16. Muitos dos novos movimentos sociais no Brasil sustentam suas identidades políticas e culturais em algum tipo de "recorte" da natureza transformada com seu trabalho; ela é ao mesmo tempo suporte da sua sobrevivência e lócus politizado da sua identidade (Almeida, 2008). 
para fazer um ato de replantio simbólico no PMJGM e transplantar 250 mudas de árvores nativas.

Nesse dia, na hora da plantação, os vizinhos convocados e outros voluntários encontraram, durante a caminhada, uma casa em construção, com sala e quartos, não pertencente ao quilombo. Ato seguido, a presidente da Amofonte, armada dos códigos de comportamento corretos sobre os usos cotidianos do mundo natural, ativou a patrulha e alertou a sua comunidade e a mídia sobre a gravidade do achado. Enviou um comunicado público, com fotos das estruturas de casas, e detalhou o estado em que se encontravam, incentivando as pessoas a se indignarem também com o que seus olhos contemplaram, pois as casas achadas pelos animados replantadores de árvores possuíam cozinha e fogão. No comunicado escrevia assim, em caixa alta: "PASMEM !!!!!!!!! COZINHA COM FOG $\tilde{A} O ” ! 17$

\section{A prefeitura da cidade insiste no descaso! Casas e fogão dentro da mata podem causar novos incêndios!!!!!! Nós vamos formar uma comissão permanente de replantio e eventos para a proteção das nossas áreas verdes. Não vamos desistir do plantio das mudas e continuaremos tentando plantar amor, consciência e responsabilidade nos corações daqueles que podem e têm o dever de cuidar do nosso meio ambiente e da nossa qualidade de vida. ${ }^{18}$}

Encontramos de novo, aqui, as concepções de "risco" e "perigo", que colocam o patrimônio ambiental sob ameaça. Aqui, a utilidade de ditas noções é a produção de fontes de legitimidade para criar uma normalização das condutas para a vida cotidiana.

Por outro lado, o que é "cozinha e fogão" senão a evocação de um cotidiano que tentava se construir num espaço monumentalizado? As fotos que circulavam no comunicado representam o vestígio de um cotidiano interrompido e atropelado, no qual deve ser protegido o monumento. É por isto que a opinião da presidente de Amofonte, com respeito ao futuro da família Pinto, é peremptória: Remoção imediata. Os elementos da impureza, já escrevia Mary Douglas, "ameaçam a boa ordem das coisas e, portanto, são repreensíveis e vigorosamente repelidos" (1991, p. 186).

Ao ser monumentalizada, a natureza é separada do humano, ao tempo que cumpre um papel de diferenciação. Em primeiro lugar, respalda material e simbolicamente o processo de diferenciação social das classes que desejam se autossegregar espacialmente de grupos sociais, como negros, favelados, pobres ou quilombolas. Em segundo lugar, suporta a diferenciação ontológica das rígidas divisões entre natureza e cultura, que não admite misturas de gêneros ou qualquer condição híbrida entre as duas instâncias.

Em ambos os casos, a tarefa de purificar a natureza torna-se também o caminho para "limpar", desse tipo de "manchas", o espaço habitado ou não. Porém, sem a existência desses conjuntos sociais, pobres, negros ou "híbridos", aqueles rituais de purificação do lugar, parafraseando Latour (2009, p. 16), careceriam de sentido, permanecendo vazios e supérfluos.

A natureza, no entanto, também guarda um lugar no cotidiano da família Pinto, e a minha pesquisa de doutorado levantou as táticas do grupo familiar para a apropriação contínua do espaço e da construção do lugar (Rodríguez, 2012). Exemplificarei isto com uma reflexão pessoal escrita por Cláudio, um dos membros da família, em que a natureza aparece, mas descrita nos termos de uma relação intimista, desenvolvida a partir da própria experiência pessoal:

Cabe à minha pessoa continuar a minha vida, no lugar que nasci e fui criado. Aguardar com paciência, assim como a paz, que se comporta em toda a natureza, com influência de toda esta riqueza que este ambiente me proporcionou. Eu usarei as ferramentas que os espíritos locais me proporcionaram até o dia de hoje. Minha grande defesa é o tempo, este sim, o grande juiz desta causa. Assim como a mata, que tentam destruir e não conseguem, assim como os espíritos, que brincaram muito comigo de criança a adulto, que me iluminaram, me deram o caminho certo, evitando o erro, eu estou certamente dotado e enraizado, e curado para continuar me defendendo dos bichos venenosos, dos que tantas vezes escapei ileso, nas aventuras da mata deste lugar de espíritos do bem. ${ }^{19}$

O relato de Cláudio enfatiza o espaço e o tempo da realidade de um presente maleável e inconcluso, baseado na experiência pessoal e nas formas de comunicação com o cosmos. Aqui se leem as circunstâncias do momento, as transformações dadas pelo tempo e as incertezas do amanhã, e a expectativa diante do que irá acontecer com a família no futuro próximo. As palavras resumem as transformações urbanas da Lagoa e as tensas relações com a vizinhança como condições sob as quais têm operado o relacionamento da família com o seu território.

$\mathrm{Na}$ época em que o conflito com a vizinhança adquiriu maior intensidade, Cláudio dirigia para sua família uma mensagem, deixada no salão do pagode (Figura 1). Tomei uma foto, que serve para ilustrar a narração desse cotidiano, imbuído dentro de um uni- 
verso natural significado a partir da convivência e proximidade.

\section{lill2 SneOPA}

uni yudo é o mínimo que poderia dizer da ajuda que recebi da famil Gostaria de pedir a todos que o momento nẫo é de questionamento quanto a nossa comunidade,talvez muitos de nós não tenhamos

$\epsilon$ endido a guerra fria que convivemos em relação ao território que

oc ipamos. Minha relação com este lugar é muito forte,pois aprendi

$m$ ita coisa com meus avós,meus pais,tirando a sobrevivência deste lugar.

Ser criado com água da nascente, ser rezado todos os dias pela minh vó,

me alimentar das frutas desta terra.Minha vó impunha o seu respeito diante

de toda familia,com sua personalidade forte.Enfim é muita coisa pra relembrar neste pequeno papel,mas digo que minha personalidade ten tudo haver com estes ensinamentos de vida que tive por puro privilégi são muitas histórias. Resumindo, peço que todos da comunidade tenh:r a conciência que precisamos de uma postura que eu chamaria de uniã Gostariamos que nos agarrássemos nessa palavra " união " esta é a ierramenta que nos permite estar aqui nesta terra até o dia de hoje. estendo aos

amigos os meus agradecimentos, pois sem a ajuda de vocês eu nao poderia dizer " obrigado "..saudade,das

jararacas, gambás, tucano, coleiros, lagartos, sabiá, rolinhas, bem-te-

vi,gatorama,tiê sangue,e da água que descia do alto da pedra através

de calha da bananeira e do bambú com os nós extraidos para melhor co. dução da água.

sou daqui,sou da terra.. josé cláudio tôrres. Filho da tia neném. obrigadc
a todos

Figura 1: Mensagem de Cláudio para sua família, afixada no salão do pagode

Fonte: Foto da autora.

Trata-se de um cotidiano que não tem como se evadir do presente. A narrativa aqui reproduzida coloca-se em contato com a realidade, que é o espaço da ação. Ao estar mais próxima da vivência empíri$\mathrm{ca}$, a cotidianidade se reinventa diariamente, a partir das "práticas pelas quais usuários se re-apropriam do espaço organizado pelas técnicas de produção sociocultural" (De Certeau, 2009, p. 41).

\section{AEIC Quilombo Sacopã: a valorização do cotidiano}

Além do PMJGM, outros complicadores para a permanência da família Pinto no lugar são suas atividades comerciais e culturais, as quais têm sido colocadas como incompatíveis com o caráter residencial da área. Contudo, esse critério não se aplica para academias, creches, restaurantes e centros de idiomas presentes na Rua Fonte de Saudade.
$\mathrm{Na}$ compreensão de que essa proibição dirige-se a sufocar os meios de sobrevivência e de expressão simbólica do Quilombo Sacopã, foi-se gestando a ideia de implementar uma Área de Especial Interesse Cultural, tendo em conta as especificidades socioculturais do grupo e sua capacidade mobilizadora em torno ao samba. As AEIC são possíveis a partir de uma emenda modificadora do Plano Diretor e estão destinadas à afetação dos "sítios culturais" que conservam referências ao "modo de vida e cultura carioca". Essa proposta argumenta que os sítios culturais são necessários à reprodução e perpetuação de manifestações culturais que ajudaram a "forjar o próprio espírito carioca ou ainda, possuem bens materiais/imateriais que contribuem para perpetuar sua memória". ${ }^{20}$

Ao reconhecer os espaços tradicionais integrantes da memória e da cultura da cidade, as AEIC pretendem tornar-se um mecanismo para ressaltar os aportes das culturas formadoras da cidade e dos espaços onde elas se realizam. O interessante é que, como instrumento de certo tipo de zoneamento e patrimonialização, é passível de ser sobreposto às unidades de conservação, às áreas de preservação permanente, às áreas de proteção do ambiente cultural ou às áreas do entorno de bem tombado (Art. 103, \$ único).

A afetação que esse tipo de emenda promete para os sítios culturais levou o vereador Eliomar Coelho (PSOL) a propor o Projeto de Lei n. 1.092/2011 para a criação da AEIC Quilombo Sacopã, proposta aprovada pela Câmara dos Vereadores do Rio de Janeiro em 2012. Se as anteriores figuras de conservação do patrimônio ambiental tinham como transfundo uma monumentalização da natureza, a criação da AEIC atentou para um discurso que dialoga com o cotidiano de um grupo social. A justificativa para o projeto argumenta que

os espaços dedicados à cultura indígena e os sítios de interesse arqueológico não podem ser consideradas meras "peças de museu". É necessário que o zoneamento urbano reconheça e fortaleça o seu caráter de formador do próprio espírito carioca conforme nos mostram inúmeros trabalhos acadêmicos e marcos históricos em toda a nossa Cidade. ${ }^{21}$

Em outras palavras, a referida emenda dá ênfase a espaços, tempos, personagens e linguagem da realidade no dia a dia, mais do que como uma projeção da tradição, como uma construção baseada na experiência própria. Mediante a declaração de "sítio cultural", o Plano Diretor registra um mecanismo dirigido à proteção do patrimônio cultural imaterial em um espaço da cidade, seja ele de domínio público ou privado. 
Contudo, o Projeto de Lei n. 1.092/2011 foi vetado pelo prefeito Eduardo Paes em $1^{\circ}$ de julho de 2012, sob o argumento de inconstitucionalidade do Legislativo ao propor ações que geram gastos ao poder executivo, pois a preservação de dito patrimônio poderia representar uma despesa. ${ }^{22}$ Mas o veto do prefeito foi derrubado numa votação cujo placar foi de 28 votos a favor contra cinco, em 7 de agosto de 2012.

Os argumentos sobre um incremento no orçamento não tinham cabimento, pois as caraterísticas da AEIC Quilombo Sacopã dependem da autonomia da própria família Pinto para realizar suas atividades culturais. A intervenção solicitada à prefeitura foi a de liberar as artes de fazer o espaço. Para o Quilombo Sacopã, significa um passo a mais para a permanência legal no espaço habitado e a manutenção das manifestações culturais: rodas de samba e feijoada. A AEIC pretende tornar objeto digno de reconhecimento as experiências cotidianas que antes passavam despercebidas. Porém, todo o processo de registro e tombamento esbarra numa certa imobilização e monumentalização do cotidiano; daí a dialética que compõe a relação entre as categorias.

Com a designação da área da AEIC Quilombo Sacopã, a cidade do Rio de Janeiro faz uma leitura do lugar a partir da história de luta do Quilombo Sacopã, também de um lugar onde o samba, a feijoada e a vida de um pequeno grupo familiar resistem à especulação imobiliária, à intolerância e à imposição de um modelo de conservação ambiental.

Com a recente consagração da cidade do Rio de Janeiro como Patrimônio Cultural da Humanidade, que declara que a originalidade da cidade é a paisagem natural e o uso que a população tem feito dele, parece necessário reconhecer os casos que integram cultura e natureza.

\section{Referências}

ALMEIDA, Alfredo Wagner Berner de. Antropologia dos Archivos da Amazônia. Rio de Janeiro: Casa 8 / Fundação Universidade do Amazonas, 2008

BECK, Ulrich. La sociedad del riesgo. Barcelona: Paidós, 1998.

BRANDÃO, Carlos Antônio Leite. Monumentalidade e cotidiano: a função pública da arquitetura. Revista de Arquitetura e Urbanismo. Ano I, n. 3, mar. 2006. Disponível em: http://mdc.arq.br/2006/03/31/monumentalidade-ecotidiano-a-funcao-publica-da-arquitetura

CHOAY Françoise. A alegoria do patrimônio. São Paulo: Editora da Unesp, 2001.
O precedente importante é que, ao ser criado pelo município e por estar localizado em uma área municipal, o PMJGM constituía um dos principais obstáculos à titulação da área como quilombo. Com a criação da AEIC Quilombo Sacopã, também de caráter municipal, caberá ao município a compatibilização das duas figuras de conservação (ver Anexos, Mapa 1).

Apesar de a promulgação da lei representar o reconhecimento oficial do respeito à diversidade cultural, como base para a manutenção da diversidade biológica no espaço urbano, a acirrada disputa está longe de terminar. Uma semana após a declaratória da AEIC Quilombo Sacopã, era realizada na Câmara Civil do Tribunal de Justiça de Rio de Janeiro a votação de um recurso impetrado pelo Incra contra o agravo feito por um dos condomínios da ladeira Sacopã, para impedir qualquer expressão musical da família Pinto.

Uma vez mais a família perdeu nos estratos judiciais e continua impedida de realizar qualquer manifestação cultural. Trata-se de uma decisão judicial que fere frontalmente o espírito da AEIC, mas que se baseia em outro tipo de leitura do lugar, a que prioriza o caráter residencial que a vizinhança tem almejado construir para seu bairro.

Ao longo destas linhas exibe-se a capacidade do lugar para receber as mais diversas inscrições e escritas que grupos e pessoas realizam sobre ele. Ao revelar os dinâmicos e múltiplos sentidos do lugar, o caso corrobora a dificuldade de se pensar em demarcações territoriais definitivas ou simbolicamente fixas para ele. Por isso, a noção de discurso resultou útil, tomado como projeção das visões de mundo que são expostas na escrita, na fala e nas representações que partem de um autor posicionado para se contrapor a outros discursos. Desde essa ótica, o lugar é foco de intensa atividade discursiva que socialmente o constrói.

CORREAA, Roberto. Monumentos, Política e Espaço. In: ROSENDAHL, Zeny; CORRÊA, Roberto Lobato. Geografias: temas sobre cultura e espaço. Rio de Janeiro: Ed. UERJ, 2005.

DE CERTEAU, Michel. A invenção do Cotidiano 1. Artes de Fazer. Petrópolis, RJ: Vozes, 2009.

DOUGLAS, Mary; WILDAWSKY, Aaron. Risk and culture: an essay on the selection of technical and environmental dangers. Berkeley: University of California Press, 1991. DIEGUES, Carlos Antônio. O mito moderno da natureza intocada. São Paulo: Hucitec, 1996.

FONSECA, Maria Cecília. Da modernização à partici- 
pação. A política federal de preservação nos anos 70 e 80 . Revista do Patrimônio Histórico, Artístico e Nacional, n. 24, p. 159, 1996.

GONÇALVES José Reginaldo. Monumentalidade e Cotidiano: Os patrimônios culturais como gênero de discurso. In: OLIVEIRA, Lucia Lippi. Cidade: História e Desafios. Rio de Janeiro: Fundação Getúlio Vargas, 2002. GONÇALVES José Reginaldo. Ressonância, materialidade e subjetividade: As culturas como patrimônios. Horizontes Antropológicos, n. 23, p. 15-36, 2005.

HARVEY David. Justice, Nature and the Geography of Difference. Oxford: Blackwell Publishers, 1996.

LATOUR, Bruno. Jamais Fomos Modernos. São Paulo: Editora 34, 1994.

LEITE LOPES, José Sérgio. Sobre processos de "ambientalização" dos conflitos e sobre dilemas da participação em Porto Alegre. Horizontes Antropológicos, n. 12, n. 25, p. 3164, jan./jun 2006.

LOVEJOY, Arthur. Essays in the History of Ideias. The Johns Hopkins Press, Baltimore; London, Cumberlege, 1948.

MARQUES, Carlos. A conquista do Paraíso. Isto é, 5 de março de 1986.

MILHORANCE, Flávia. Quilombo Sacopã: Verde e disputado. O Globo, Rio de Janeiro, $1^{\circ}$ jul. 2010.

MORAES, Antônio Carlos. Valor, Natureza e Patrimônio Natural. Ciência e Ambiente. Santa Maria, RS, v. 28, p. 107-204, 2004.

PIAZZINI, Carlo Emilio. Cronotopos, memorias y lugares: una mirada desde los patrimonios. In: PIAZZINI,
Carlo Emilio; ARANGO, Vladimir Montoya. Geopolíticas: espacios de poder y poder de los espacios. Medellín: La Carreta Editores, 2008.

OLLAGNON, Henry. Estratégia patrimonial para a gestão dos recursos e os meios naturais. Enfoque Integral da gestão no meio rural. In: VIEIRA, Paulo; WEBER, Jacques (Orgs.) Gestão dos Recursos Naturais Renováveis e Desenvolvimento. Novos desafios para a pesquisa ambiental. São Paulo: Corkz, 1997.

RJTV GLOBO. Polêmica na Fonte da Saudade. Rio de Janeiro, 10 mar. 2008. Disponível em: http://rjtv.globo. com/Jornalismo/RJTV/0.MUL341465-9097.00.html RODMAN, Margaret. Empowering Place: Multilocality and Multivocality. In: LOW, Setha; LAWRENCEZUÑIGA, Denise (Eds.). The antropology of space and place. Oxford: Blackwell Publishing, 2010.

RODRÍGUEZ, Luz Stella Cáceres. Memórias e Narrativas da Preservação nos Quilombos da Cidade do Rio de Janeiro. Tese (Doutorado em Geografia). Programa de Pós-graduação em Geografia da Universidade Federal do Rio de Janeiro. Rio de Janeiro, 2012.

ULLOA Astrid. Pensando verde: surgimento y desarrollo de la consciencia global ambiental. In: PALACIOS, Germán; ULLOA, Astrid. Repensando la naturaleza: encuentros y descuentros diciplinarios en torno a lo ambiental. Bogotá: Colciencias, 2003.

ZUKIN, Sharon. Paisagens Urbanas Pós-modernas: Mapeando Cultura e Poder. In: ARANTES, Antonio (Org.). O espaço da diferença. São Paulo: Papirus, 2000.

\section{Naturaleza monumentalizada, cotidiano politizado: la construcción discursiva del lugar en la comunidad cimarrona de Sacopã}

\section{Resumen}

La disputa decurrente de la presencia de Quilombo Sacopã en un área instituida como el parque Municipal José Guilherme Merquior (PMJGM) en la ciudad de Rio de Janeiro, se analiza desde la tensión entre la monumentalidad y la vida cotidiana. Como parte del discurso patrimonial, estas categorías de pensamiento descubren las lógicas de apropiación y construcción de lugar a través de relatos e historias que se desdoblan en acciones de preservación del medio ambiente y de la memoria cultural. El Quilombo Sacopã, que esta conformado por miembros de la familia Pinto que se organizaron para defender su permanencia en el lugar que habitan desde 1920, reclaman para sí el derecho a la morada y la propiedad de la tierra y en este proceso se enfrentan, entre otros, con los intereses ambientalistas de activistas y residentes del vecindario. El caso pone en jaque la comprensión del lugar como algo listo, estático y perfectamente delimitado; pues como construcción social, el lugar esta constituído por la acumulación de diversas camadas de significados y se presenta internamente dinámico y heterogéneo, con configuraciones dialécticas de relativas permanencias y cambios en los procesos socio-espaciales.

Palabras clave: lugar, quilombo urbano, patrimonio cultural y natural, monumentalidad, cotidiano. 


\title{
Monumentalized natures, everyday politicized: the discursive construction of the place in the Quilombo Sacopã case
}

\begin{abstract}
The appellant disputed the presence of Quilombo Sacopã in an area established as a Municipal Park José Guilherme Merquior (PMJGM) in the city of Rio de Janeiro in 2001, is parsed from the tension between monumentality and daily life. As part of the patrimonial discourse, these categories discover the logics of appropriation and construction of place through narratives and stories that unfold on environmental preservation actions and cultural memory. The Quilombo Sacopã is conformed by members of the family Pinto who organized themselves to defend their permanence in place inhabiting since 1920; they claim the right to housing and land ownership and that faced by, among others, with the environmental interests of activists and neighborhood residents. The Case threatens the understanding of the place as something ready, static and perfectly delimited; as social construction, the place presents itself internally dynamic and heterogeneous, with dialectic of settings for stays and changes in socio-spatial processes.
\end{abstract}

Key words: place, urban morron, cultural and natural heritage, monumentality, everyday life.

Data de recebimento do artigo: 30/01/2013

Data de aprovação do artigo: 16/05/2013 


\section{Anexos}

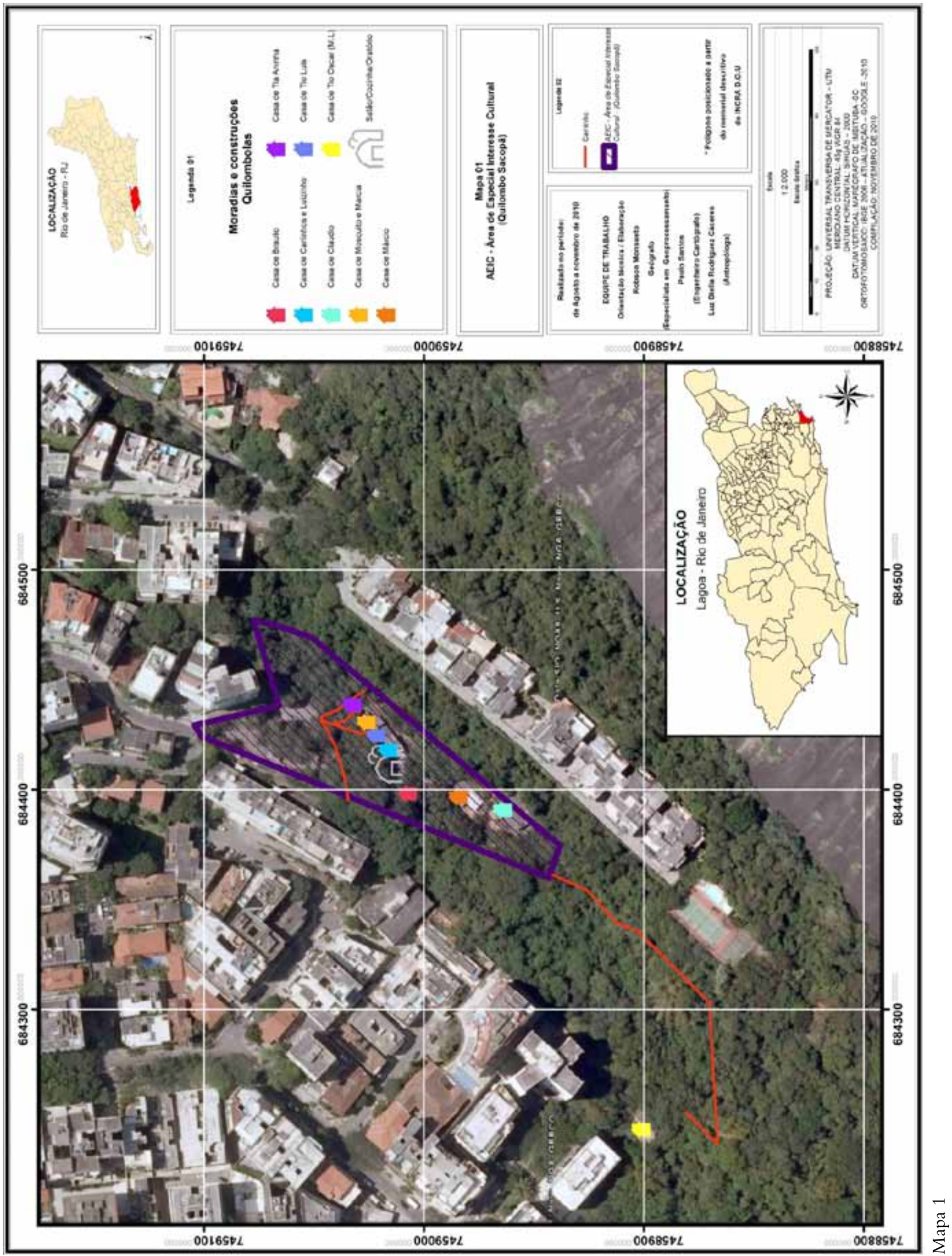




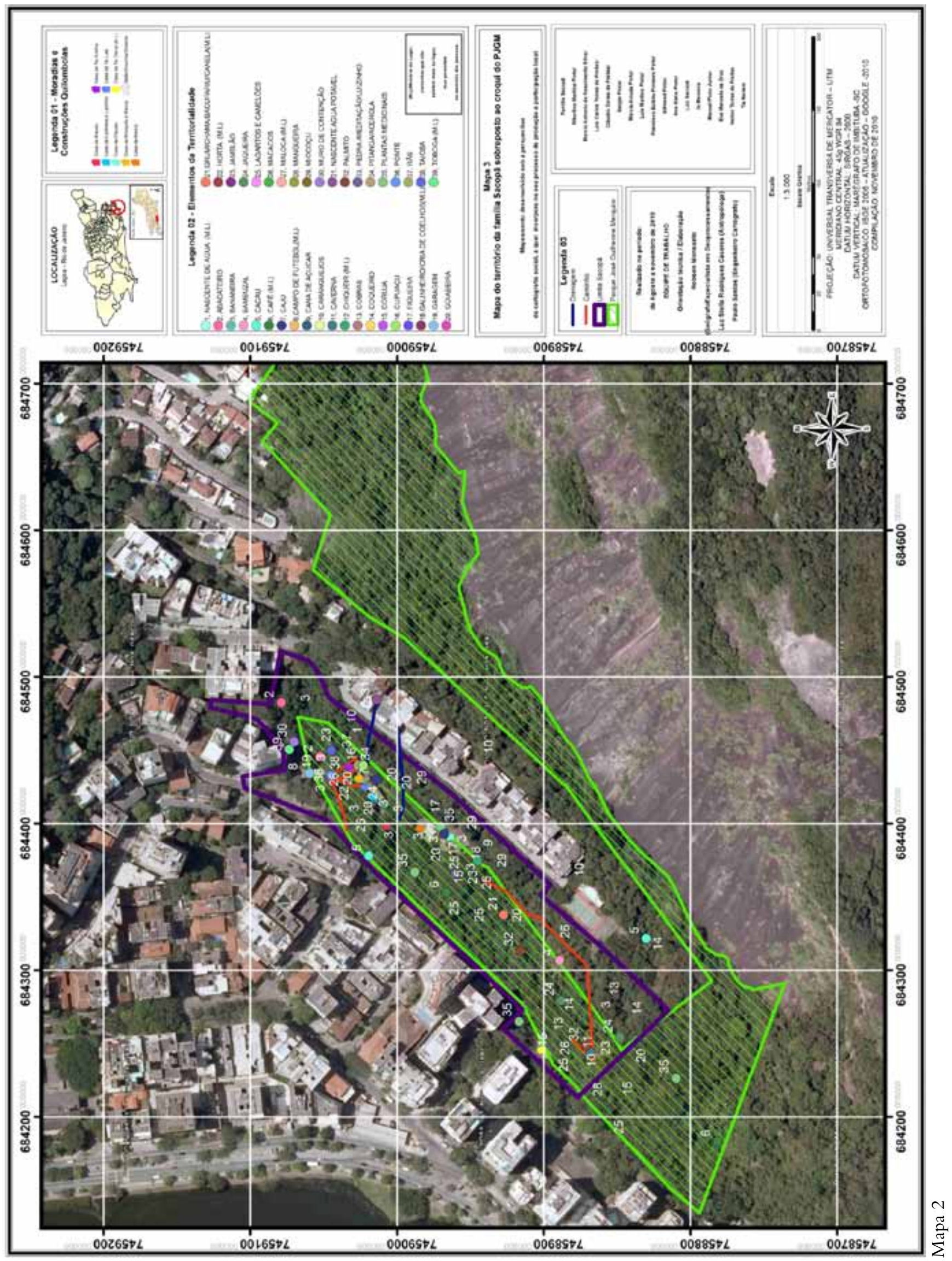




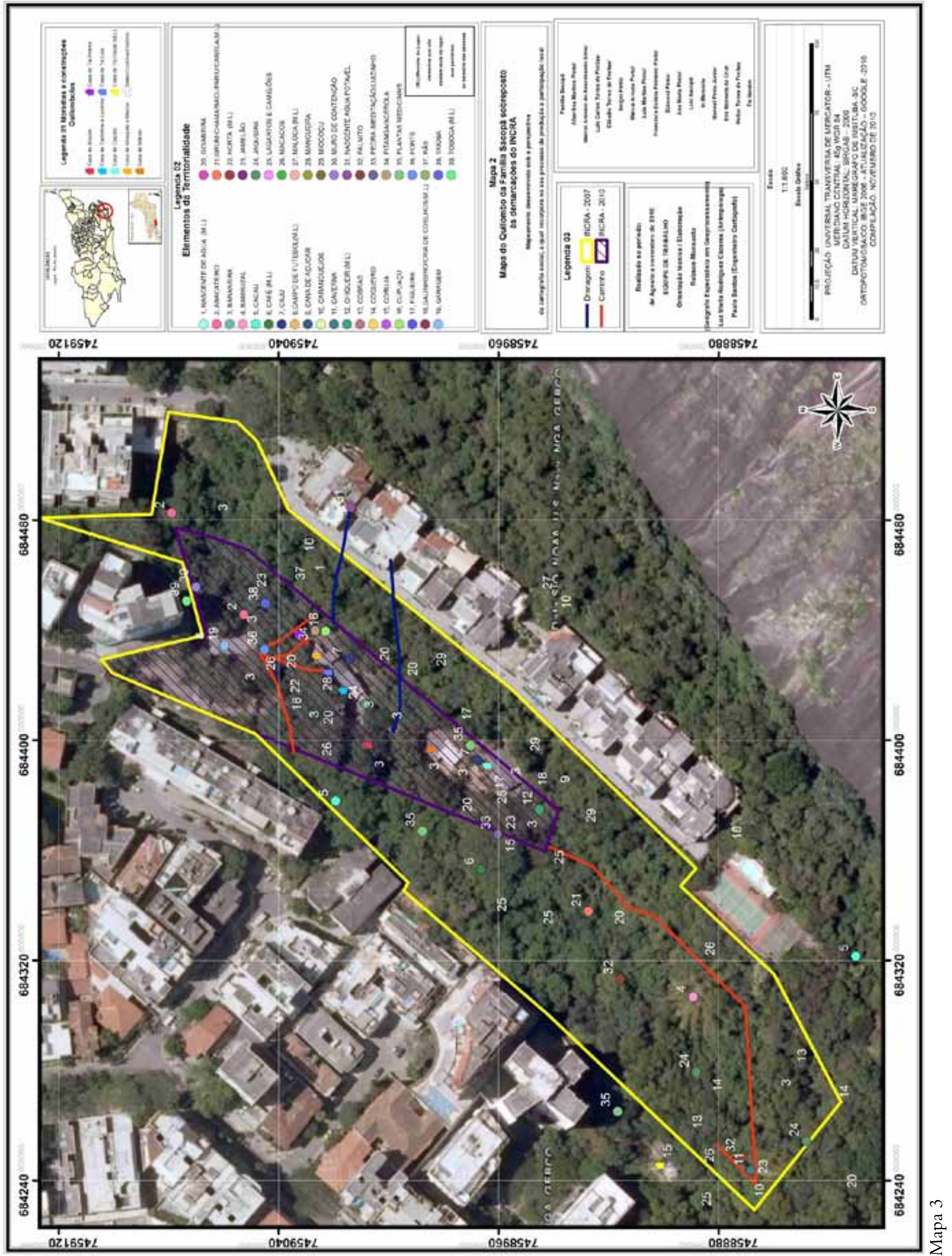

